\title{
Research on Seismic Behavior of High-pier and Long-span Rigid Frame-continuous Combination Bridge With Corrugated Steel Webs
}

\author{
Wenzhou Wang ${ }^{1, a}$, Yili Wang ${ }^{2, b}$, Zhan Yang ${ }^{3, \mathrm{c}}$ and Bin $\mathrm{Li}^{4, \mathrm{~d}}$
}

${ }^{1}$ Guangdong Nanyue Transportation Investment \& Construction Co. Ltd, Guangzhou, Guangdong, 516000, China

${ }^{2}$ School of Transportation, Southeast University, Nanjing, Jiangsu, 210096, China

${ }^{3}$ School of Transportation, Southeast University, Nanjing, Jiangsu, 210096, China

${ }^{4}$ Guangdong Nanyue Transportation Investment \& Construction Co. Ltd, Guangzhou, Guangdong, 516000, China

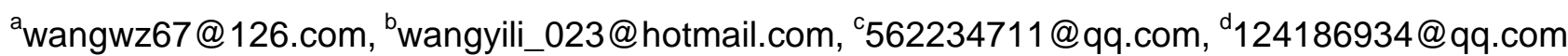

Keywords: bridge engineering, seismic, corrugated steel webs, frame-continuous combination, high-pier, Pushover analysis

Abstract: Based on a long-span rigid frame-continuous combination bridge with corrugated steel webs, the seismic behavior of finite element model built by Midas Civil is analyzed through Pushover method, and the result is compared with the result from nonlinear time-procedure analysis. The outcome indicates that the bridge is able to meet the demand of E2 earthquake, and the results from the different methods are generally identical.

\section{Introduction}

As a new type of composite structure consisting of steel and concrete, prestressed concrete composite box girder with corrugated steel webs has been widely accepted by bridge designers for its excellent mechanical properties, convenient construction and pleasing shape. There have been more than 200 prestressed concrete box girder bridges with corrugated steel webs that are completed or under construction. Rigid frame-continuous composite beam bridges which are combination of continuous beam bridge and continuous rigid frame bridge usually use rigid frame with pier-beam consolidation in several middle spans and set bearings in the others. Recently, experts on structure have done sufficient research on flexural, anti- torsion, shearing and stability capacity, however, there is a lack of research on seismic behavior. [1] The research on the seismic behavior of a long-span rigid frame-continuous combination bridge with corrugated steel webs will provide reference for the similar projects and it will benefit the extension and development of the bridges with corrugated steel webs in China.

\section{Engineering Background}

No.2 Yujing Bridge is a high- pier and long-span rigid frame- continuous combination bridge with corrugated steel webs. It is designed as a variable- section, 5- span rigid frame-continuous combination bridge with corrugated steel webs. The span arrangement is $58 \mathrm{~m}+3 \times 100 \mathrm{~m}+58 \mathrm{~m}$. The bridge is divided into 2 parts. The overall width is $24.5 \mathrm{~m}(0.5 \mathrm{~m}$ concrete guard bar+ $10.75 \mathrm{~m}$ carriage way $+0.75 \mathrm{~m}$ corrugated guard bar $+0.5 \mathrm{~m}$ medial strip $+0.75 \mathrm{~m}$ corrugated guard bar $+10.75 \mathrm{~m}$ carriage way $+0.5 \mathrm{~m}$ concrete guard bar). The vertical view is showed in Fig. 1.

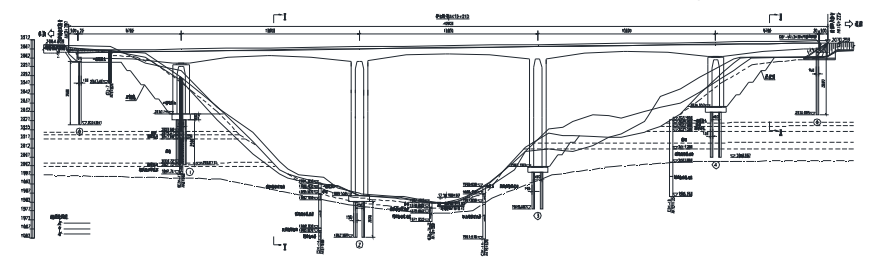

Fig. 1 Bridge vertical view (unit: $\mathrm{cm}$ ) 
The section of a single girder is single box, box girder top baseboard is arranged in parallel, the corrugated steel webs are arranged vertically, and the two box girders are symmetrical. The width of a single bridge box girder is $12 \mathrm{~m}$, while the width of the baseboard is $6 \mathrm{~m}$. The height of the girders and the thickness of the baseboard changes by the two parabolic laws from the middle to the root. In the middle, the height of the girders is $3.2 \mathrm{~m}$ and the thickness of baseboard is $0.25 \mathrm{~m}$. In the root, the height of the girders is $6.8 \mathrm{~m}$ and the thickness of baseboard is $0.8 \mathrm{~m}$. The length of the flange of box girder cantilever is $3 \mathrm{~m}$, and the thickness of the cantilever changes from $0.2 \mathrm{~m}$ to $0.7 \mathrm{~m}$. The typical cross section of the main girder is showed in Fig. 2.

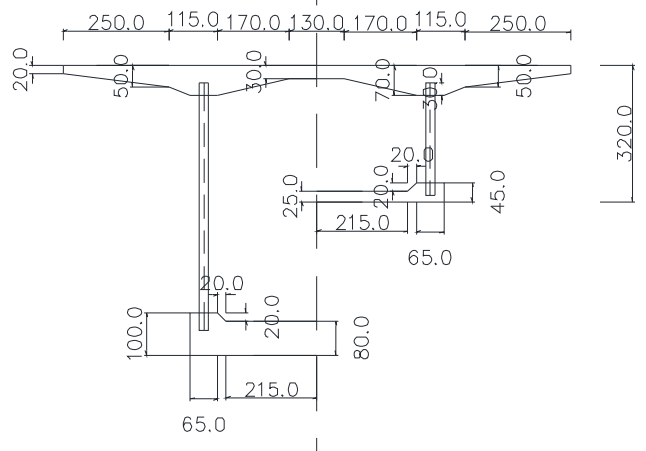

Fig. 1 The typical cross section of the main girder(unit: $\mathrm{cm}$ )

In this bridge, 1600-type corrugated steel webs is adopted, the length of it is $1.6 \mathrm{~m}$, the height of it is $0.22 \mathrm{~m}$, the width of horizontal panel is $0.43 \mathrm{~m}$, horizontal folding angle is $30.7^{\circ}$, and the buckling radius is $15 \mathrm{t}$ ( $\mathrm{t}$ is for the thickness of the corrugated steel webs). The size is showed in Fig. 3, and the thickness includes $12 \mathrm{~mm}, 14 \mathrm{~mm}, 16 \mathrm{~mm}, 18 \mathrm{~mm}$ and $20 \mathrm{~mm}$. The material of the corrugated steel webs is Q345D. Angle connectors and double PBL connectors are applied in connecting the corrugated steel webs, top board and baseboard.

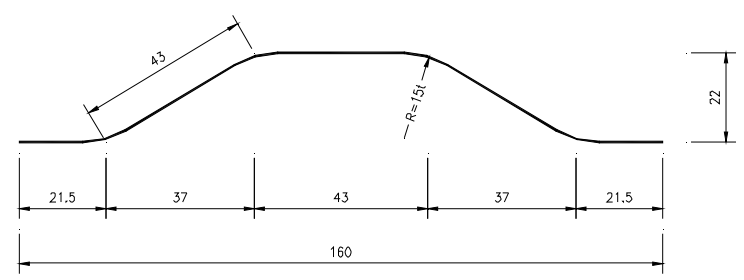

Fig. 3 Corrugated steel web drawing (unit: $\mathrm{cm}$ )

The longitudinal prestressed steel in box girders exists both internally and externally. The internal prestressed steel is $15 \varphi s 15.2$ steel strand and the under tension control stress is $1395 \mathrm{MPa}$. The external prestressed steel is $19 \varphi s 15.2$ steel strand and the under tension control stress is $1116 \mathrm{MPa}$.

The NO.1, NO.2, NO.3, NO.4 piers are hollow piers with 0.9m- thick wall. The length in transverse external dimension is $6 \mathrm{~m}$ while the length in external dimension along the bridge is $9 \mathrm{~m}$. There are 6 embedded piles whose diameter is $1.5 \mathrm{~m}$ under the piers. The height of NO.1 pier and NO.4 pier is $28 \mathrm{~m}$, the length of piles is $25 \mathrm{~m}$. The height of NO.2 pier is $75 \mathrm{~m}$ and the height of NO.3 pier is $60 \mathrm{~m}$, the length of their piles is $25 \mathrm{~m}$. The thickness of cushion cap is $3 \mathrm{~m}$, the plane dimension is $10 \mathrm{~m} \times 10 \mathrm{~m}$. Among 
them, the NO.2 pier and NO.3 pier have rigid frame connection, and the NO.1 pier and NO.4 pier have sliding bearing connection. The type of the support is GPZ(II)4DX.

\section{The main steps of Pushover analysis}

1. Establish structural model, the physical parameters of the components and the restoring force model, etc.;

2. Calculate the internal forces of the units, and combine the transverse load and vertical load;

3. Choose a loading method of lateral force, load it on the structure system, increase the level of force until one or a group of units yielded;

4. For cracking or yielding units, modify their stiffness, and then add a level of load, making the new unit yielded;

5. Repeat (3), (4) step, until the structure reaches the maximum limit;

6. Draw the relationship between the pier bottom shear force and the displacement of the pier top, and the Pushover curve can be obtained, as shown in Fig. 4. [2][3]

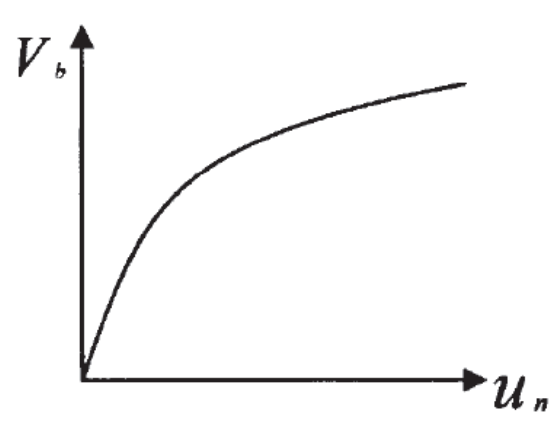

Fig. 4 Pushover curve

\section{Pushover analysis of No.2 Yujing Bridge}

Finite element model. According to the characteristics of the structure, the structure is divided into 165 units and 172 nodes, and the Civil Midas 2010 is used to build the analysis model of box girder with corrugated steel webs. The static finite element model of the bridge is shown in Fig. 5. 


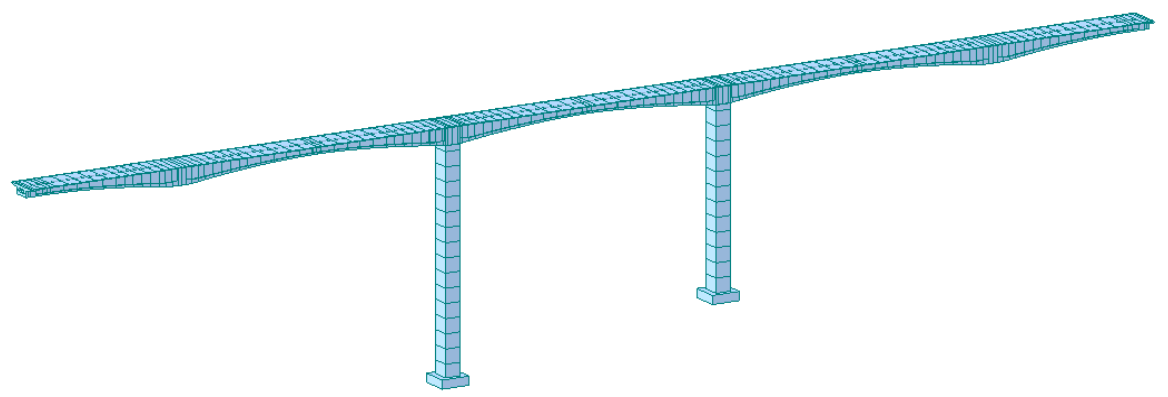

Fig. 5 Static finite element model of No.2 Yujing Bridge

Pier bottom shear- pier top displacement curve. Based on Pushover analysis, the pier bottom shear- pier top displacement curve of the bridge pier is obtained, as shown in Fig. 6 Fig. 7. The seismic performance analysis of longitudinal and transverse direction of the structure is carried out.

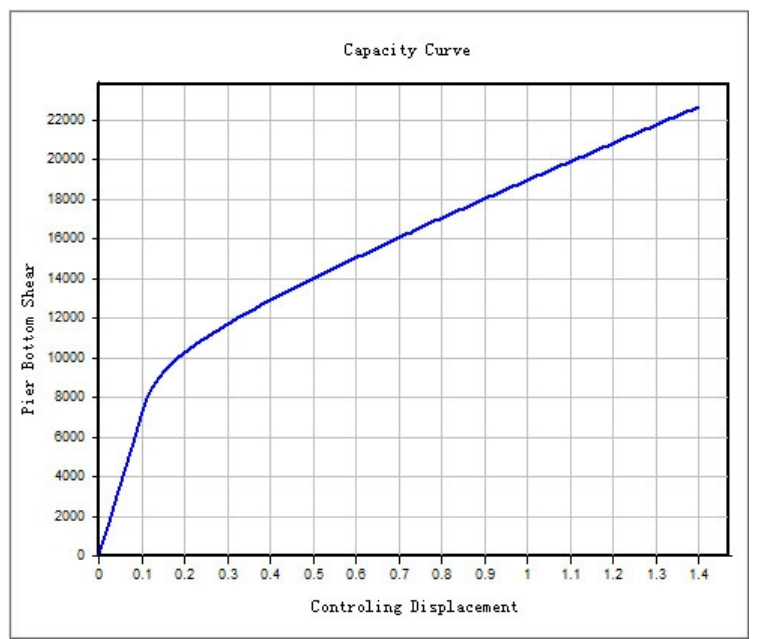

Fig. 6 Longitudinal pier bottom shear- pier top displacement curve

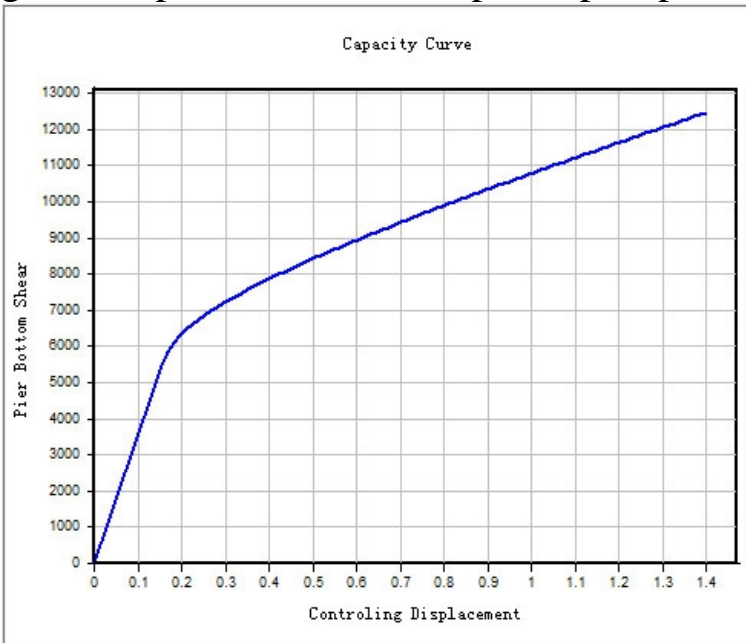

Fig. 7 Transverse pier bottom shear- pier top displacement curve

As shown in Fig. 6 to Fig. 7, when longitudinal pier bottom shear is $9000 \mathrm{kN}$ and pier top displacement is $0.140 \mathrm{~m}$, the model begins to enter elastic plasticity stage; when transverse pier bottom shear is $6118 \mathrm{kN}$ and pier top displacement is $0.182 \mathrm{~m}$, the model begins to enter elastic plasticity stage. Before this point, the slope of pier bottom shear- pier top displacement curve is approximately a constant. After this point, the slope of the curve begins to change significantly.

Seismic performance analysis. Through the Pushover analysis of the bridge, the pier bottom shear- pier top displacement curve is converted to the capacity spectrum curve. Put the capacity spectrum curve and demand spectrum curve into a same coordinate system, and the intersection point of the two curves is the performance point. 


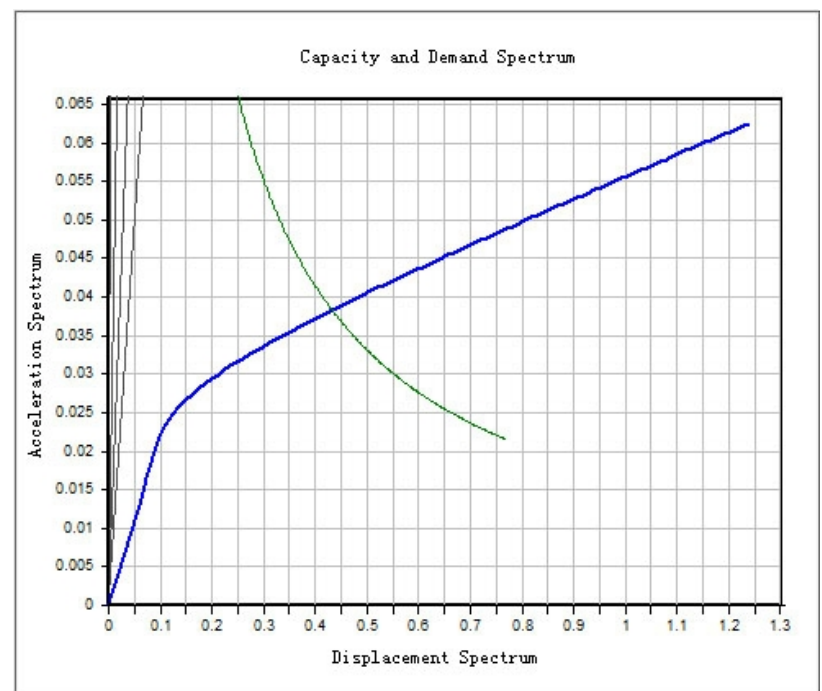

Fig. 8 Longitudinal capacity and demand spectrum curve

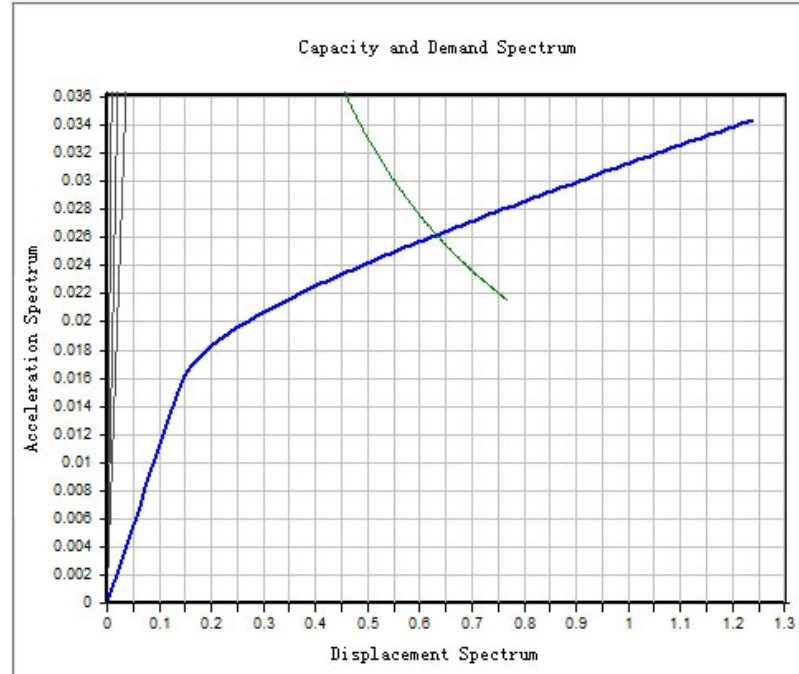

Fig. 9 Transverse capacity and demand spectrum curve

Table 1 Structural performance point parameter

\begin{tabular}{c|c|c}
\hline Loading condition & Longitudinal & Transverse \\
\hline Spectral acceleration $\mathrm{S}_{\mathrm{a}}(\mathrm{g})$ & 0.038 & 0.026 \\
\hline $\begin{array}{c}\text { Spectral displacement } \\
\mathrm{S}_{\mathrm{d}}(\mathrm{m})\end{array}$ & 0.433 & 0.632 \\
\hline Pier bottom shear(kN) & 13890 & 9496 \\
\hline $\begin{array}{c}\text { Displacement of controling } \\
\text { point }(\mathrm{m})\end{array}$ & 0.488 & 0.714 \\
\hline
\end{tabular}

In the longitudinal direction, when the bridge gets performance point, the pier bottom shear is $13890 \mathrm{kN}$, the pier top displacement is $0.488 \mathrm{~m}$, the spectral acceleration is $0.038 \mathrm{~g}$, the spectral displacement is $0.433 \mathrm{~m}$. Fig. 8 shows that when the bridge gets performance point, the structure is in the elastic and plastic phase. In the transverse direction, when the bridge appears performance point, the pier bottom shear is $9496 \mathrm{kN}$, the pier top displacement is $0.714 \mathrm{~m}$, the spectral acceleration is $0.026 \mathrm{~g}$, the spectral displacement is $0.632 \mathrm{~m}$. Fig. 9 shows that when the bridge appears performance point, the structure is in the elastic and plastic phase. From the above analysis, we can know that the performance points exist both in longitudinal and transverse direction. It can meet the requirements of E2 seismic. When the performance points appear, the bridge is into the elastic plastic stage. 
Contrast with nonlinear time history method. The results of Pushover method are compared with the results of nonlinear time history analysis, as shown in Table 2.

Table 2 Result comparison between Pushover method and nonlinear time history analysis

\begin{tabular}{c|c|c}
\hline \multirow{2}{*}{ mode } & \multicolumn{2}{|c}{ Pier bottom shear $(\mathrm{kN})$} \\
\cline { 2 - 3 } & Pushover & nonlinear time history \\
\hline longitudinal & 13890 & 10785 \\
\hline transverse & 9496 & 9518 \\
\hline
\end{tabular}

The table shows that the calculation results from Pushover method and the calculation result from nonlinear time history method can basically be consistent, so the Pushover method is of certain accuracy for the seismic performance evaluation of beam bridge. Moreover, the Pushover analysis method is simpler than the general nonlinear time history analysis, and it is easy to be mastered and applied in the design. It is also a simple seismic calculation method in the design of the bridge. However, when the Pushover method is used to calculate, the multi degree of freedom system is treated as a single degree of freedom system and the nonlinear structures are replaced by a series of linear systems, which will lead to a reduction of accuracy [4]. In order to meet the needs of engineering design, the Pushover method still needs to be revised.

\section{Conclusion}

Pushover analysis method is much simpler, compared to the nonlinear dynamic history analysis method, and it can get relatively accurate numerical results. In the bridge seismic design in the future, it will be regarded as a simple seismic calculation method. However, it still need further modifying to improve its accuracy.

\section{Reference:}

[1] X. Xie: Seismic Response Analysis and Seismic Design of Bridge Structures (China Communications Press, Beijing 2006) (In Chinese )

[2] P. Yang, D. Li, Y.M. Li, M. Lai: Research Progress of Static Elastic Plastic Analysis (Push-over) Method for Aseismic Structures( Journal of Chongqing Jianzhu University, 2000) (In Chinese)

[3] W.H. Liu: Elastic Plastic Seismic Response Analysis of Long Span Continuous Rigid Frame Bridge (Changsha University of Science and Technology, 2008) （In Chinese )

[4] W. Wei, Q.M. Feng: Comparative Study of Several Push-over Analysis Methods (Earthquake Engineering and Engineering Vibration, 2002) (In Chinese) 